\title{
DESIGN SPECIFICATIONS OF A GENERIC SUPPLY CHAIN SIMULATOR
}

\author{
Shigeki Umeda \\ Management School \\ Musashi University \\ 1-26 Toyotama-kami Nerima,Tokyo, \\ 176-8543, Japan
}

\author{
Y. Tina Lee \\ Manufacturing System Integration Division \\ National Institute of Standards and Technology \\ Gaithersburg, MD 20899-8260, U.S.A.
}

\begin{abstract}
This paper describes a design specification for a generic, supply-chain-simulation system. The proposed simulation system is based on schedule-driven and stock-driven control methods to support the supply chain management. The simulation system includes three processing modes: business process flows, material process flows, and information process flows. The paper also discusses interface data requirements for the proposed supply-chain-simulation system.
\end{abstract}

\section{INTRODUCTION}

The primary goal of supply chains is to provide manufactured products to end-customers. Modern manufacturing enterprises must collaborate with their business partners in the activities of designing, manufacturing, and distributing their products. Supply chain management is one of the hottest topics in production planning and control areas. Supply chain planning is, in a sense, restructuring a business system for supply chain members to collaborate with each other by exchanging information.

This restructuring frequently involves fundamental decisions regarding business activities and, more importantly, these decisions must be made in full collaboration with business partners. In making these decisions, each enterprise must develop a flexible management system to survive in today's competitive business environment. Supply chain managers, in both planning phases and operational phases, face various kinds of problems, such as capacity planning, production planning, inventory planning and others. Systematic approaches are needed to support planning and control of such supply chain systems.

Simulation is an effective tool to optimize designs and operations of manufacturing and logistics systems. The strength of simulation, in comparison with mathematical programming methods (Geoffrion and Grave 1974) or stochastic models (Cohen and Lee 1988), is to enable users to observe and analyze the dynamic behaviors in the target system.

Realization of supply chain simulation revealed several technical difficulties, including modeling of business process and data communication, representation of a synchronization mechanism of information-flow with material-flow, and building simulation models.

Modeling requirements and a framework for a generic simulation system that supports design, planning and operation of supply chain systems have been identified (Umeda and Jain 2004). It is recommended that common control methods of manufacturing systems are also applicable to supply chain modeling. The common control methods identified are "schedule-driven control" and "stock-driven control," which are based on material management policies in discrete manufacturing systems (Arnold and Chapman 2001). This paper applies these concepts to simulation modeling. The following sections give detailed descriptions of models, which simulate activities and data flows of an individual chain member. Major topics include the design specifications of a generic supply chain simulator and its interface data requirements.

\section{SIMULATION MODEL DESCRIPTIONS}

A generic, supply-chain simulation system is proposed based on the modeling requirements and modeling framework that has been identified previously (Umeda and Jain 2004). This section describes fundamental designs for the proposed simulation system. The following sub-sections describe the system's configuration and management.

\subsection{Supply Chain System Configuration}

There are many types of supply chain systems. Our previous work classified chain members into six types, based on their business behaviors (Umeda and Jain 2004). These six types of chain members are "supplier," "source," "storage," "deliverer," "consumer," and "planner." The proposed simulation system also uses this classification method to represent all supply chain members.

The function the particular chain member performs is italicized in the discussion that follows. Supplier produces products or parts by using materials that another supplier provided. Source is a special supplier that generates materi- 
als. Every material flow in a chain starts with a source. Storage is a supplier that stores materials until another chain member requires them. An example of storage is a warehouse in a distribution network. Deliverer transports materials from a particular chain member to another. A $3^{\text {rd }}$ Party Logistics (3PLs) company is one of the typical examples of deliverer. Consumer gives purchase orders and receives products. Planner makes operational plans for all chain members in order to deliver products to consumers just in time. Planner controls other chain members by giving orders to them or sending signals to replenish materials. Planner often plays a role as a supervisor of suppliers. Table 1 provides a definition and example of each chain member type. Figure 1 is an example of representation of a supply chain system by using the abstracted chain members. This chain includes three $1^{\text {st }}$-tier and two $2^{\text {nd }}$-tier suppliers, a final product plant, a retailer that possesses a warehouse, a transporter, a $3^{\text {rd }}$ party logistics company that directly delivers products to customers, and three consumers.

\subsection{Control Methods of Chain Members}

Schedule-driven and stock-driven control methods are used to support the supply chain management in the proposed simulation system. This section briefs these two control methods.

\subsubsection{Schedule-Driven Control}

Schedule-driven control uses a production schedule, the socalled "Master Production Schedule" (MPS), which thesupply chain planner generates. The chain planner regularly collects demand data from marketing channels in a constant cycle time. It periodically updates the MPS by us-

Table 1: A Classification of Supply Chain Members

\begin{tabular}{|l|l|l|}
\hline Chain Member & \multicolumn{1}{|c|}{ Definition } & \multicolumn{1}{|c|}{ Example } \\
\hline Supplier & $\begin{array}{l}\text { An organization that provides materials in the } \\
\text { chain. }\end{array}$ & $\begin{array}{l}\text { Parts manufacturers, material manufac- } \\
\text { turers, parts assemble manufacturers, } \\
\text { and final products plants. }\end{array}$ \\
\hline Source & $\begin{array}{l}\text { An organization that starts the material-flows in } \\
\text { the chain. Parts and material suppliers, which } \\
\text { material-flows start in the chain. }\end{array}$ & Material manufacturers. \\
\hline Storage & $\begin{array}{l}\text { An organization that holds materials, parts, or } \\
\text { products. }\end{array}$ & $\begin{array}{l}\text { Warehouses, transportation bases, store- } \\
\text { houses, wholesalers, and plant ware- } \\
\text { houses. }\end{array}$ \\
\hline Deliverer & $\begin{array}{l}\text { An organization that transports products, parts, } \\
\text { and/or materials between members. }\end{array}$ & $\begin{array}{l}3^{\text {rd }} \text { party logistics companies, UPS, and } \\
\text { post office are examples. }\end{array}$ \\
\hline Consumer & $\begin{array}{l}\text { An organization or individual who acquires } \\
\text { products. }\end{array}$ & $\begin{array}{l}\text { Buyers, consumers, and trading compa- } \\
\text { nies are examples. }\end{array}$ \\
\hline Planner & $\begin{array}{l}\text { An organization that controls material-flows and } \\
\text { information-flows in the chain. }\end{array}$ & $\begin{array}{l}\text { A headquarters of a final products } \\
\text { manufacturer, and a supply chain con- } \\
\text { trol center. }\end{array}$ \\
\hline
\end{tabular}

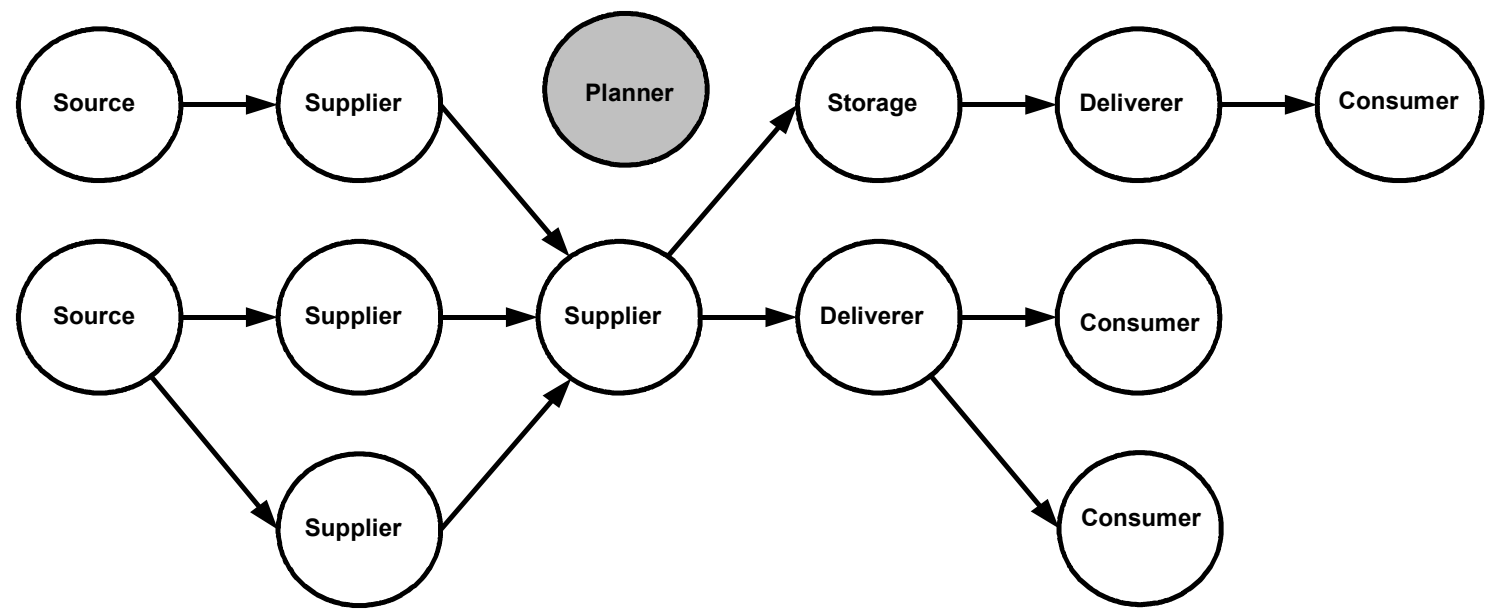

Figure 1: An Example of a Supply Chain System Represented with Abstract Notations 
ing accumulated, demand-prediction data. MPS is a schedule about when finished-goods are delivered to consumers. To generate the MPS, the chain planner generally bases on demands forecast, production plan, availability of materials, and availability of capacity.

The main function of the chain planner is to give periodic operational orders to supply chain members by using MPS and Bills Of Materials (BOMs). The schedule-driven suppliers regularly work with the planner. As shown in Figure 2, the chain planner uses schedule-driven control to repeat the above activities cycle. The activities of planner are summarized as follows:

1. It receives purchase orders from consumers.

2. It accumulates this purchase data.

3. It generates future demand predictions by using the accumulated demand data.

4. It updates MPS by using the predicted demand and feedback data from supply chain members.

5. It gives orders (sourcing, manufacturing, and shipping) to corresponding chain members.

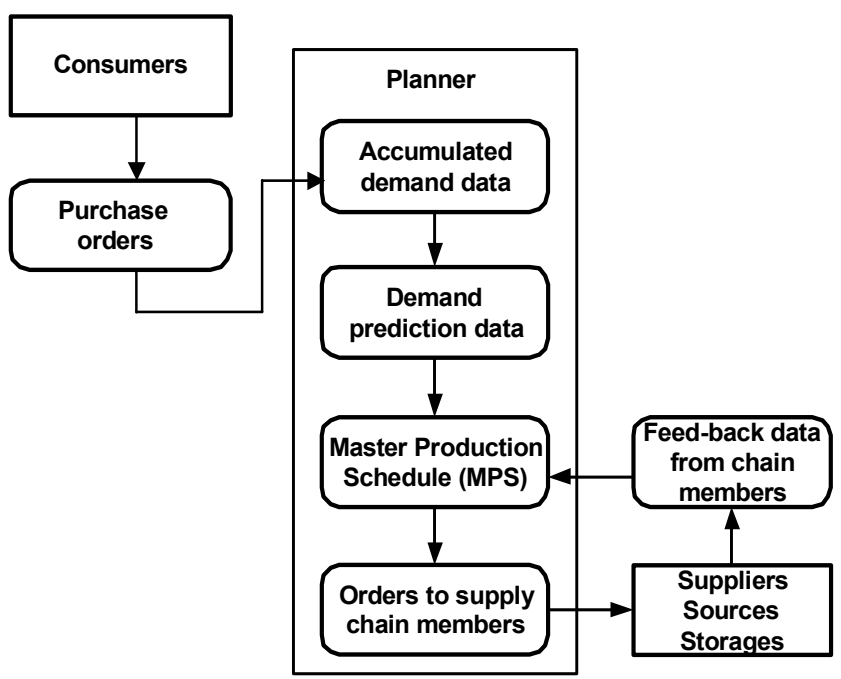

Figure 2: Schedule-Driven Supply Chain Control

\subsubsection{Stock-Driven Control}

While a schedule-driven supplier works according to the orders sent by the planner, a stock-driven supplier gives orders to itself. "Stock-driven" control method uses stock information of a particular chain member. This member is usually located downstream in the material flow. This member should own two parameters of input material stock volume: stock-replenishment level and stock-volume level. These two parameters are determined by the planner, which observes the changes of demands. A stock-driven supplier autonomously replenishes material inventories based on these two parameters.
Each "Stock-driven" member continuously observes stock volume at a particular chain member. It starts to produce products when the stock volume is smaller than the stock-replenishment level, and continues to work until the stock volume is equal to or greater than the stock-volume level. Figure 3 is a diagram of the stock-driven, supply chain control. This stock-driven supplier generally works according to the following operational sequences:

1. It periodically observes stock-volume data of a particular chain member.

2. It starts producing when the stock volume goes down below the stock-replenishment level.

3. It stops producing when the stock volume reaches the stock-volume level.

Planner dynamically changes the stock-replenishment level and stock-volume level according to the market demand transition.

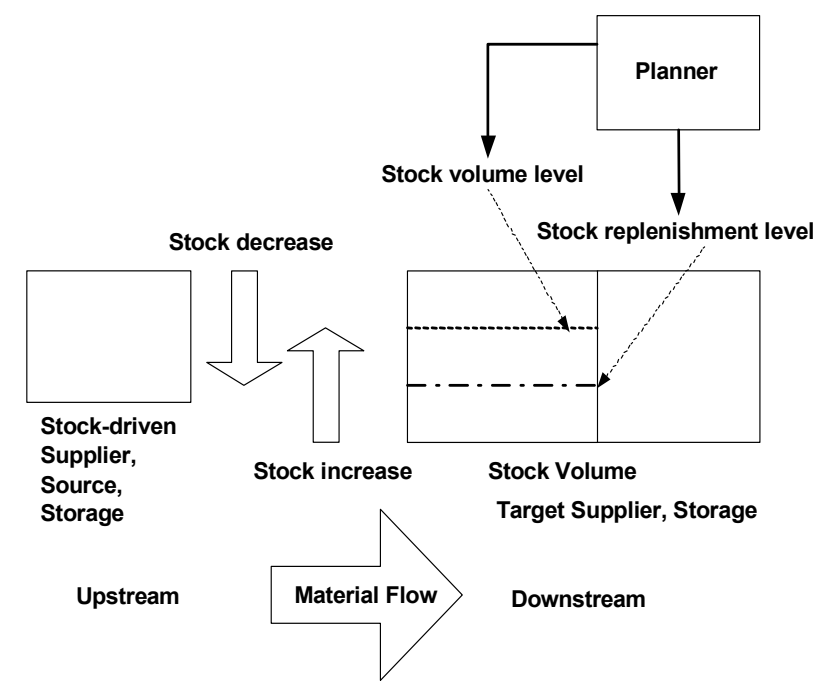

Figure 3: Stock-Driven Supply Chain Control

\section{SUPPLY CHAIN SIMULAITON SYSTEM}

This section provides a design specification of the proposed supply chain simulation system. The characteristics, requirements, responsibilities, activities sequence, and performance that each supply chain member holds, for either the schedule-driven or stock-driven methods, are described. There are nine types of players/components: scheduledriven source, stock-driven source, schedule-driven supplier, stock-driven supplier, schedule-driven storage, stockdriven storage, deliverer, planner, and consumer. The following sub-sections, 3.1-3.9, specify detail attributes of each component. Information included in each sub-section is presented in the following categories:

- Material input: The material this component receives from another components. 
- Information Input: The information this component receives from another components.

- Material output: The material this component provides to another components.

- Information output: The information this component provides to another components.

- Pre-defined information: The information about the constraints of this component in view of the material capacity.

- Activities sequence: A sequence of activities performed by this component.

- Performance measure: A set of measurements representing the component's performance within the supply chain.

\subsection{Schedule-Driven Source}

Schedule-driven source (see Figure 2) receives and executes sourcing orders from the planner, which maintains an MPS. When it is busy, a new order waits to be executed at an order queue. A schedule-driven source receives sourcing orders from the planner, and responses to it. It also gives delivery orders to deliverer.

\subsection{Stock-Driven Source}

Stock-driven source (see Figure 3) continuously observes the stock volume of a particular chain member. When the materials volume of the target supplier becomes lower than the stock-replenishment level, this source generates materials in its own buffer. Work continues until the stock volume reaches the stock-volume level. When it finishes a sourcing operation for a predefined lot-size, it sends a delivery order to the attached deliverer. This shipment will stop once the volume of materials at the specified supplier reaches or exceeds the stock-volume level.

\subsection{Schedule-Driven Supplier}

Schedule-driven supplier (see Figure 2) receives manufacturing orders from the planner, which maintains an MPS. The schedule-driven supplier executes the manufacturing orders received from the planner. When it is busy, the new incoming order waits at the order queue. Materials stay in the supplier's buffer until the delivery order is executed.

\subsection{Stock-Driven Supplier}

Stock-driven supplier (see Figure 3) continuously observes the stock volume at a particular chain member. When the materials volume of the target supplier is lower than the stock-replenishment level, this supplier executes orders. The work continues until the stock volume reaches the stock-volume level. When it finishes manufacturing operation for a pre-defined lot-size, it sends a delivery order to the attached deliverer. This manufacturing will stop once the volume of materials at the specified supplier reaches or exceeds the stock-volume level.

\subsection{Schedule-Driven Storage}

Schedule-driven storage (see Figure 2) receives orders from the planner, which maintains an MPS. A chain planner often plans to store materials for future demand fluctuation. The schedule-driven storage plays an important role in such scenarios. Schedule-driven storage receives materials and saves them when materials are received from the up-stream suppliers. Schedule-driven storage sends a delivery order to the attached deliverer when it receives the shipment orders from the planner. When it is busy, a new incoming order waits at the order queue.

\subsection{Stock-Driven Storage}

Stock-driven storage (see Figure 3), as well as scheduledriven storage, receives materials and saves them when materials arrive from its up-stream supplier. While schedule-driven storage provides materials through the orders received from the planner, the stock-driven storage provides the materials from a particular supplier's buffer. Stock-driven storage receives materials and saves them, when materials arrive from the up-stream suppliers. Stockdriven storage continuously observes the stock volume in a particular chain member. When the materials volume in the target supplier becomes lower than the stock-replenishment level, this storage generates a delivery order and sends it to the attached deliverer. It stops working when the volume of materials at the specified suppliers reaches or exceeds the stock-volume level.

\subsection{Deliverer}

Deliverer serves as a generic physical material transporter. The deliverer in the simulation model performs no function other than carrying materials from one site to another according to a given order. When it receives the delivery orders from the supplier (usually an immediate up-stream supplier), the deliverer carries materials from upstream to downstream. When it does not own enough materials to be delivered, it waits for materials.

\subsection{Planner}

Major tasks are providing predictions of future market demands and giving orders to the chain members. The order sent by the planner may be for sourcing, supplying, or shipping. Predictions of market demands in actual business practice is a complex task. The predictions are based on various types of demand data, including non-numerical data such as knowledge-oriented data and heuristics. Further discussion of prediction approaches is beyond the scope of this paper and the proposed simulation only 
adopts statistical techniques for making such predictions. This section describes input and output information the planner requires, such as: accumulated demand data, demand prediction, and orders and materials levels.

\subsubsection{Demand Data Accumulation}

The accumulated demand data is used to forecast demands. Each demand-data record describes one purchase order with information including order identification, consumer, order date, delivery due date, product type, and product quantity. With accumulated demand data, total volume of each specific product ordered in a particular day can be calculated and used for predicting future demands.

\subsubsection{Demand Prediction}

There are many demand forecasting methods using statistical techniques. One of the most popular methods is the exponential smoothing method. An advantage of this method is that the new data can be generated with any weight indicated. The weight given to the latest demand is called a smoothing constant and is represented by alpha $(\alpha)$. This value is always expressed as a decimal from 0 to 1.0 . The formula for calculating the new forecast is as follows:

New forecast

$=\alpha *($ latest demand $)+(1-\alpha) *($ previous forecast $)$

Table 2 represents an example of demand forecasting calculations with $\alpha=0.8$ and eight planning phases. Listed in the table is information for each phase, including phase number, actual demand, calculated forecast, predicated demand, and the difference between a predicated demand and an actual demand. Demand value is expressed in lots. Figure 4 is a graph that compares forecasted and actual data. Initial value of actual demand data and forecast value are both 70 (lots) in this case. Means of actual demand and predicted demand are $66.25+/-2.625$ and $68.875+/-15.14$, respectively. This prediction method often produces large errors when the changes of demand trends are increased (see Phases 5 and 8 in Figure 4).

The importance in this operation is a concept of "planning phase," or planning cycle-time. In the rest of this sub- section, the current phase is treated and represented as the (i)-th phase.

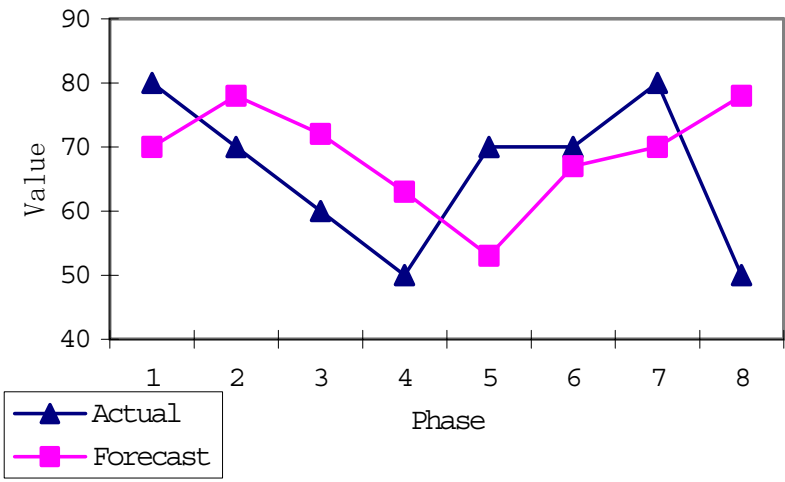

Figure 4: Comparison between Forecast and Actual Demands

It is a difficult problem to decide how often a planner predicts market demands. Suppose that the planner gives orders daily; the data bias (variance of the data) would be greater if the prediction were calculated weekly. Several methods are considered to reduce data variance; one of them would be to set a demand prediction term longer than ordering cycle-time.

\subsubsection{Master Production Scheduling}

MPS represents how the chain plans to produce with specific configurations, quantities, and dates. MPS must take into account the forecast, production plan, backlog, availability of material, availability of capacity, management policies and goals, etc.

\subsubsection{Ordering and Stock Level Control}

When the planner receives purchase orders from the customer, this order data is divided into two flows. The first is an input to shipment preparation; the other is an input to demand predictor. Shipment preparation is based on the production strategy used. The demand predictor generates a forecast of final products. Figure 5 shows a mechanism to generate production orders. The required forecast term is

Table 2: An Example of Demand Forecast Calculation

\begin{tabular}{|l|r|r|r|r|r|r|r|r|r|}
\hline Phase term (i) & 0 & 1 & 2 & 3 & 4 & 5 & 6 & 7 & 8 \\
\hline Actual demand & 70 & 80 & 70 & 60 & 50 & 70 & 70 & 80 & 50 \\
\hline $\begin{array}{l}\text { Forecast } \\
\text { calculated }\end{array}$ & $(70)$ & $56+14$ & $64+14$ & $56+16$ & $48+15$ & $40+13$ & $56+11$ & $56+14$ & $64+14$ \\
\hline $\begin{array}{l}\text { Predicated } \\
\text { demand }\end{array}$ & 70 & 78 & 72 & 63 & 53 & 67 & 70 & 78 \\
\hline $\begin{array}{l}\text { Difference } \\
\text { (predicated, actual) }\end{array}$ & & -10 & 8 & 12 & 13 & -17 & -3 & 10 & 28 \\
\hline
\end{tabular}


directly correlated with supply chain structure (Chain depth). The first-tier supplier at the $n$-th planning phase works based on the prediction data at the $n+1$-th planning phase. This is because the materials produced at the firsttier suppliers in the $n$-th phase will be provided to the final product plant for use in the $(n+1)$-th phase. Similarly, the second-tier supplier at $n$-th phase works based on the prediction data at $(n+2)$-th phase.

Production strategies may include assemble-to-order (ATO), make-to-order (MTO), configure-to-order (CTO), make-to-stock (MTS), ship-to-stock (STS), etc. The selection of a control method (schedule-drive control or stockdriven control) is determined by the type of production strategy used. Three supply chain scenarios are described here.

1. ATO or MTO with schedule-driven control: The chain is operated according to the ATO or MTO production strategy. In this case, a schedule-driven supplier produces final products to be delivered directly to consumers. The customers' orders are directly transformed into an assembling (manufacturing) order to a final product plant (Umeda and Jain 2004). The planner gives manufacturing orders to the schedule-driven members, and the schedule-driven member gives a delivery order to the deliverer.

2. MTS with schedule-driven control: The chain is operated according to the MTS production strategy. The customer's orders are transformed directly into a shipment order to a distributor. In this case, final products are stored in a scheduledriven storage. The planner gives shipment orders directly to the schedule-driven storage.

3. STS with stock-driven control: The chain is operated according to the STS production strategy. In this case, a stock-driven supplier, the closest supplier to consumers, autonomously works according to the requirements of stock-replenishment-level data and stock-volume data. The planner gives no order to the supplier of final products; however, it sets the "stock-replenishment level" and "stockvolume level" for its stock-driven chain members. When the material shortage rate increases at this member, the planner raises the member's stockreplenishment level. On the other hand, when the material inventory volume increases at this member, the planner reduces the stock-volume level.

\subsection{Consumer}

Consumer gives purchase orders to the planner. It also receives products from other chain components (e.g., supplier or storage) by way of a deliverer.

\section{INTERFACE DATA REQUIREMENTS FOR SUPPLY CHAIN SIMULATION MODEL}

This section specifies the information required for the supply chain simulation proposed in this report. A requirement

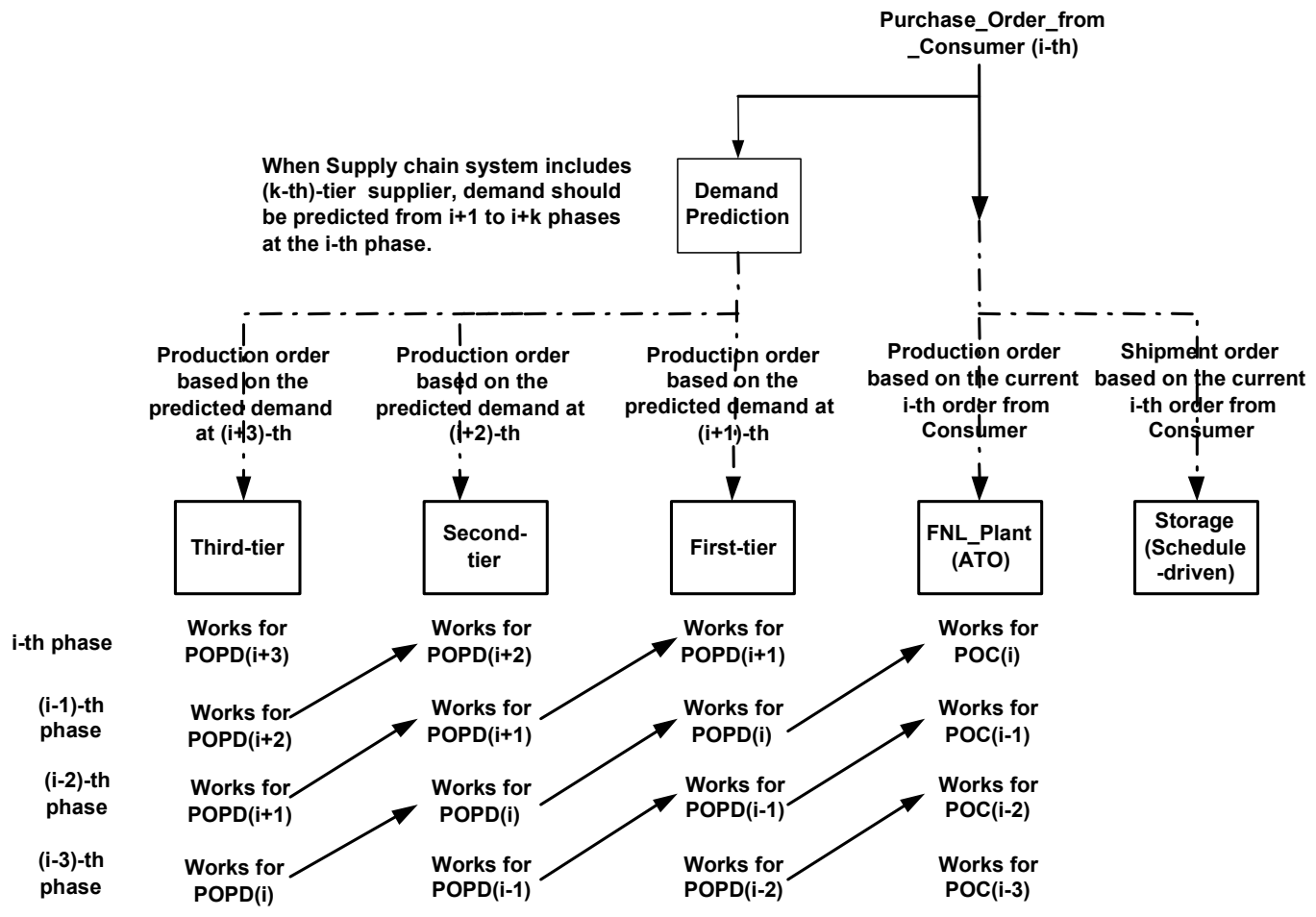

Figure 5: Order Generation Mechanism in Supply Chain Planner 
analysis of the supply chain simulation has been performed. This analysis focuses on the data that needs to be exchanged between supply chain members. As a result, a set of data requirements needed for exchange amongst these members has been identified. Local data required by an individual supply chain member is not included in the requirements list. The data requirements are grouped into thirty entities or units of functionality:

- Supply chain: Supply chain defines the supply chain's identification, products, and each member's role. The supply chain role is an enumeration of consumer, deliverer, planner, source, supplier, and storage.

- Product volume data: Product volume data identifies the quantities of products available during each specified time period for various purposes. The purpose may be for a demand forecast, a manufacturing capacity estimation, a stockreplenishment level and stock-volume level assignments, an MPS update, or a stock availability record. Demand forecast predicts the volume of demand for each end product. Manufacturing capacity estimation approximates the volume of each product produced. Stock-replenishment level and stock-volume level are set by a planner but belong to a stock-driven supplier; these two parameters are keys to start or stop a production. MPS specifies at which end products are produced. Stock availability specifies the volume of each product carried over from the previous business phase.

- Supplier data: Supplier data specifies the materials the supplier organization requires and the products the supplier provides, including manufacturing lot size, manufacturing lead-time, attached deliverer organization, target supplier organizations, and the stock-replenishment level and stock-volume level of each target supplier organization. It also keeps track of manufacturing orders received, manufacturing order responses sent, and delivery orders sent. Information about materials and products' charges and discount options may also be included.

- Source data: Source data specifies the type and volume of parts that the source organization carries, sourcing lot size, sourcing lead-time, attached deliverer organizations, and the stock-replenishment level and stock-volume level of each target supplier organization. It also keeps track of sourcing orders received, sourcing order responses sent, and delivery orders sent. Information about each part's price and discount options may also be included.

- Consumer data: Consumer data specifies the products' volume that the consumer organization might consume during a particular business phase.
It also keeps track of purchase orders sent, order lead-time, products received time, and product volume of each delivery received.

- Deliverer data: Deliverer data specifies the deliverer organization's transportation methods and resources including resource type, resource count, delivery lot size, and delivery time. It also keeps track of delivery orders received, delivery order responses, and upstream supplier organizations, as well as downstream supplier organizations. Information about loading equipment requirement, labor requirement, and transportation lead-time may also be included.

- Storage data: Storage data specifies the type and volume of materials and storage lot size that the storage organization carries. Information included in storage data are shipping lot size, shipping lead-time, attached deliverer organizations, target supplier organizations with supplied materials, and the stock-replenishment level and stockvolume level of each target stock-driven supplier. It also keeps track of shipping orders received, shipping order responses, and delivery orders. Each material's price and discount options may also be included.

- Planner data: Planner data maintains planning cycle time, purchase orders received from consumers, manufacturing orders and shipping orders sent out from the planner, and feed-back data received from chain members. It also keeps track of demand prediction data, the stock-replenishment level and stock-volume level at each stock-driven supplier, and MPS data.

- MPS data: MPS data specifies an MPS policy, planning phases, and a set of schedules for final products to be delivered to consumers.

- Supply chain order data: Supply chain order data describes a generic order that is submitted, received, and/or processed for the supply chain. A supply chain order may be a purchase order, a manufacturing order, a sourcing order, or a storing order. Information about the order, including identification, type, date, originator organization, receiver organization, priority, due date, and type and volume of ordered products are included in the supply chain order data entity. Order priority is an enumeration of regular and urgent orders.

- Supply chain order status data: Supply chain order status data describes the status of the generic supply chain order, which may be a purchase order, a manufacturing order, a sourcing order, or a storing order. Information about the planned shipping date, shipping method, and subtotal charge for each product are included in the supply chain order status data entity. 
- Shipping order data: Shipping order data describes a shipping order for materials or products to be delivered to or picked up from a supply chain organization. Information about the shipping order, including date, type, originator and receiver organizations, pick up time and location, delivery time and location, shipping materials/products, shipment value, transportation cost, and total shipment weight are included in the shipping order data entity. The shipping order type is an enumeration of new, revised, and cancelled orders.

- Shipping order status data: Shipping order status data specifies the shipping status of a particular shipping order. Information about the shipping order status, including identification, generation date, origination organization, status code, and original shipping order identifier are included in the shipping order status entity. The shipping order status code is an enumeration of pending, in-process, completed, and cancelled orders.

- Delivery request data: Delivery request data describes a transportation service request for accomplishing a particular shipping order. Information about the delivery request, including identification, generation date, request originator and receiver organizations, shipping order identifier, and delivery type are included in the delivery request data entity. The delivery type is an enumeration of pickup and delivery.

- Delivery status data: Delivery status data describes the status of a transportation request service. Information about the delivery status, including identification, date, originator organization, status code, and original delivery request identifier are included in the delivery status data entity. The delivery status code is an enumeration of pending, in-process, completed, and cancelled orders.

- Delivery report data: Delivery report data summarizes the completion of a particular delivery request service. Information about the delivery request, including identification, date, delivered materials/products, and organizations that receive and send deliveries are included in the delivery report data entity.

- Performance report data: Performance report data summarizes a supply chain's performance based on a simulation run. Performance data includes statistics regarding production, materials flow, resource utilization, staff utilization, and inventory. Production statistics identify the total products the origination produced in a particular simulation run. Materials-flow statistics identify the organization's throughput, average flow time, and queuing time for each material used in the simulation run. Resource utilization statistics identify the organization's machine utilization (e.g., utilization level, process time, maintenance time, and down time). Staff utilization summarizes each staff's utilization (e.g., utilization level, regular hours, overtime hours, and absentee hours). Inventory statistics identify the inventory's average work-in-process value and inventory turnover rate during the simulation run.

- Organizations*: Organizations is used to maintain the organizational structure, contacts and address information for the manufacturing organization and its customers and suppliers.

- Calendars*: Calendars identifies the shift schedules that are in effect for a period of time, including breaks and holidays.

- Resources*: Resources describe all the resources that may be assigned to tasks in the shop. The resource types available in the machine-shop environment include: stations and machines, cranes, employees, and tool and fixture catalog items.

- Skill definitions*: Skill-definitions lists the skills that an employee may possess and the levels of proficiency associated with those skills.

- Setup definitions*: Setup definitions typically specifies tool or fixture setups on a machine. Tool setups are typically the tools that are required in the tool magazine. Fixture setups are workholding devices mounted on the machine. Setups may also apply to cranes or stations.

- Operation definitions*: Operation definitions defines the operations that may be performed at a particular station or group of stations in the shop.

- Maintenance definitions*: Maintenance definitions defines preventive or corrective maintenance to be done on machines or other maintained resources.

- Parts*: Parts provides elements for part specifications, group technology codes, customers, suppliers, as well as links to bills of materials, process plans, drawings, part models, and other references.

- Bills of materials*: Bills of materials crossreferences the parts and quantities required in a hierarchical bill-of-materials structure.

- Inventory*: Inventory identifies the instances and locations for parts, materials, tools, and fixtures inventory.

- Probability distributions*: Probability distributions specifies distributions that are used to vary processing times, breakdown and repair times, availability of resources, etc.

- Units of measurement*: Units of measurement describes various measurement units used in the file. For example, the measurement may be specified for distance, speed, mass, time duration, or currency. 
- Cost summary*: Cost summary specifies a summary of costs at various stages including estimation, planning, and actual expenses. The categories of costs include material cost, labor cost, equipment-usage cost, inventory cost, and transportation cost. The element of equipment depreciation, which was missing from the machine shop information model, will be added into this model's data structure.

A machine-shop information model has been developed to support the exchange of shop data between various manufacturing software applications, including simulation. The purpose of developing this model is to use the model's data structures for managing actual production operations and for simulating the machine shop. About twenty major entities and thirty commonly used entities are included in the machine-shop information model. The entities designated by $*$ have been previously defined by McLean et al (McLean et al. 2004). More detailed information regarding those entities designated by * in the above list are provided with the machine-shop information model.

\section{CONCLUSION}

A supply-chain-simulation system is proposed in this paper. The design of each component and supply chain member included in the system is described. Planning, control, and operation of the supply chain are discussed. Interface data requirements that support information exchange and sharing amongst chain members are identified. The proposed system has been designed to be generic in order to simulate any typical discrete-event manufacturing in a supply chain. The proposed simulation has also been designed to preserve independence from both usage and implementation. Implementation independence allows users to select their own simulation language. Currently, further work has begun on design of interface requirements' data structures, and development and execution of a prototype supply chain simulation system. It is anticipated that the proposed system will be refined in order to enhance the system's performance and implementers' satisfaction.

\section{DISCLAIMER}

No approval or endorsement of any commercial product by the National Institute of Standards and Technology is intended or implied. The work described was funded by the United States Government and is not subject to copyright.

\section{REFERENCES}

Arnold, T. J.R., and S. N. Chapman. 2001. Introduction to Materials Management. 4th edition. Prentice Hall, Inc., USA.
Cohen, M.A., and H. L. Lee. 1998. Strategic analysis of integrated production-distribution systems: Models and methods. Operations Research, 36(2), pp. 216-228.

Geoffrion, A.M., and G. W. Grave. 1974. Multi-commodity distribution system design by Benders Decomposition, Management Science. 20(5), pp. 822-844.

McLean, C., T. Lee, G. Shao, and F. Riddick. 2004. Shop Data Model And Interface Specification, to be appeared, NISTIR, National Institute of Standards and Technology, Gaithersburg, Maryland.

Umeda, S., and S. Jain. 2004. ISSS: Integrated Supply chain Simulation System -- Modeling Requirement and Design Issues, to be appeared, NISTIR, National Institute of Standards and Technology, Gaithersburg, Maryland

\section{AUTHOR BIOGRAPHIES}

SHIGEKI UMEDA is a professor for Management Informatics in the Management School at Musashi University, Tokyo, Japan. His research interests include supply chain design issues and discrete-event simulation. His email address is shigeki@cc.musashi.ac.jp.

Y. TINA LEE is a computer scientist in the Manufacturing Simulation and Modeling Group at the National Institute of Standards and Technology, United States Department of Commence. Her e-mail address is leet@cme. nist.gov. 